\title{
Causes of keel bone damage and their solutions in laying hens
}

\author{
A. HARLANDER-MATAUSCHEK ${ }^{1}$, T.B. RODENBURG ${ }^{2}$, V. SANDILANDS ${ }^{3}$, \\ B.W. TOBALSKE ${ }^{4}$ and M.J. TOSCANO ${ }^{5}$ *
}

${ }^{1}$ Animal and Poultry Science, University of Guelph, 50 Stone Road E., Guelph, ON, Canada N1G 2W1; ${ }^{2}$ Animal Breeding and Genomics Centre, Wageningen University, PO Box 338, 6700 AH Wageningen, The Netherlands; ${ }^{3}$ Avian Science Research Centre, SRUC, Auchincruive Campus, Ayr, KA6 5HW, United Kingdom; ${ }^{4}$ Field Research Station at Fort Missoula, Division of Biological Sciences, University of Montana, Missoula, MT 59812, USA; ${ }^{5}$ Research Center for Proper Housing: Poultry and Rabbits (ZTHZ) Division of Animal Welfare, VPH Institute, University of Bern, Burgerweg 22, 3052 Zollikofen, Switzerland

*Corresponding author: Michael.toscano@vetsuisse.unibe.ch

Keel bone damage (KBD) is a critical issue facing the contemporary laying hen industry due to the likely pain leading to compromised welfare and reduced productivity. Recent reports suggest that KBD, while highly variable and likely dependent on a host of factors, extends to all housing systems (including traditional battery cages, furnished cages and non-cage systems), genetic lines, and management styles. Despite the extent of the problem, the research community remains uncertain as to the causes and influencing factors of KBD. To combat these issues, the current review was produced following discussions from the 1st International Keel Bone Damage Workshop held in Switzerland in April 2014. This exercise sought to assess current knowledge, foster novel collaborations, propose unique methodologies and highlight the key areas where innovative research is needed. The following paper is based on the content of those discussions and presents nine recommendations for future research efforts.

Keywords: keel; fracture; damage; welfare; bone; laying hen

\section{Introduction}

The high frequency of damage seen in the keel bone (a bone extending from the sternum) of laying hens within commercial systems represents one of the greatest welfare problems facing the industry (FAWC, 2010; 2013). Beyond the obvious welfare issue of gross skeletal deformity, concern stems from the likely associated pain indicated by the decreased latency to descend from a perch (Nasr et al., 2012a; 2012c, 2014). One type of KBD, keel fractures (KF), sometimes referred to as 'old breaks', can be 
defined as breaks in the bone that will typically manifest as a callus around the fracture site after a few days; KF may also involve sharp, unnatural deviations, or bending of the bone (Wilkins et al., 2004). The problem of keel damage is clearly widespread with similar yet highly variable levels reported in various countries, such as Switzerland (Kappeli et al., 2011); UK (Wilkins et al., 2011); The Netherlands, Belgium, Germany (Rodenburg et al., 2008; Heerkens et al., 2013) and Canada (Petrik et al., 2015). Keel bone damage (KBD) extends across genetic lines (Kappeli et al., 2011) and all types of housing systems (Wilkins et al., 2011; Petrik et al., 2015)including organic production systems (Bestman and Wagenaar, 2014). Despite their ubiquity, the causes and influencing factors of KBD remain largely unknown to the research community, a circumstance that severely handicaps the development of effective strategies to reduce their occurrence and severity.

To identify critical areas where research is needed and coordinate the multiple ongoing and future research efforts of laboratories, the International Keel Bone Damage Workshop was organised by the University of Bern in April 2014. This manuscript serves to highlight the workshop dialogue and harness the collective energies of the research community towards reducing KBD in laying hens by formulating key recommendations for forthcoming research.

\section{Recommendation 1 - A uniform method of evaluating KBD should be employed with relevant criteria to ensure reliability of results}

Currently, evaluating KBD in live birds is principally done by palpation; a method that originated primarily from two papers (Wilkins et al., 2004; Scholz et al., 2008) which have since been adopted by a variety of labs. While broadly similar in their classification of damage, key differences exist and require resolution. Most critically, Wilkins et al. (2004) only discussed KF while Scholz et al. (2008) included deviations of the keel (deformations from a theoretically flat, two dimensional plane; also referred to as curving or bending). Given that KF and deviations likely result from different causal factors (i.e. sudden impacts causing large forces versus sustained and small forces, respectively), this lack of clarity represents a major obstacle in combining results to allow for comprehensive interpretation of the problem. The multiple methods in use are a challenge in resolving KBD, hindering our abilities to compare findings and resulting in needless and inefficient replication. We recommend development of a uniform assessment of KBD that assesses KF and deviations where each uses a binary scale of whether damage is present. The system should be developed in concert with an associated scoring sheet which should be made publicly available to facilitate the amalgamation of data produced by the labs conducting related research.

Beyond defining the presence or absence of damage, identifying grades of severity is needed to determine the types of KBD that are a concern. Research that can provide reliable and consistent markers to classify KBD in grades of severity that are grounded in meaningful criteria relevant to animal welfare (e.g., pain caused by fracture) and/or other spheres of concern (e.g. productivity) is essential.We also recommend adoption of training criteria for persons assessing KBD (particularly by palpation which is more subjective than dissection) to ensure greater reliability of results. A system employed by assessors with appropriate training can produce results that are more useful in determining true occurrence of damage and evaluating interventions. The method of assessment, including free access to a developed scoring form, the described definitions for the various forms of damage, as well as criteria and training for palpation, is described elsewhere (Casey-Trott et al., in press). 


\section{Recommendation 2 - Investigate low energy, non-collision events as a source of $\mathbf{K F}$}

High energy events within non-cage systems provide a likely mechanism for KF that have been suggested to result from collisions with elements of animal housing such as perches (Scott et al., 1997; Moinard et al., 2004a; Sandilands et al., 2009; Wilkins et al., 2011). Counter-intuitively, KF frequently occur in cage systems where there exists seemingly limited opportunities for dynamic loading as might occur during collision. Thus, improving our understanding of the sources of KF will require insight of dynamic as well as static events. The mechanisms of KF in cage systems are likely not exclusive to this environment, i.e. static mechanisms are likely to cause damage in non-cage systems as well, and thus deserve investigation to provide a more comprehensive understanding of the sources of KBD.

Although commercial laying hens kept in enriched cages and non-cage systems have opportunities for weight-bearing activities, birds' skeletons remain fragile because of a combination of nutritional, environmental and genetic factors (Whitehead, 2004a). It would be worthwhile to test whether seemingly innocuous, quasi-static activities can induce KF. While perching, hens place considerable forces on their keels which is in contact with the perch (Pickel et al., 2011) and certain perch designs or material may result in severe keel bone deviations and perhaps also KF (Pickel et al., 2010). This mechanism would be similar to compression fractures in osteoporotic bones of humans, which have been shown to occur spontaneously or with normally innocuous activities, such as sneezing or twisting (Kondo, 2008). Furthermore, application of modeling techniques, including finite-element models (Tomaszewski et al., 2010) that represent the keel bone, would be useful to provide an understanding of the static and dynamic loading patterns in the bone.

More generally, a broader understanding of the keel, using a comparison of relevant bird phylogenies, could be helpful to establish the morphological capacity of the keel and how modern housing conditions exceed that capacity. It would be useful to assess keel integrity in relation to the functional morphology of diverse avian clades that exhibit significant variation in hindlimb/forelimb modules, keel morphology, flight style, and use of natural perches (Heers and Dial, 2012).

\section{Recommendation 3 - Investigate the relationship between deviations and KF}

A keel with deviations may lead to unequal bone loading during wing-flapping and concentration of strain energy in ways that increase the risk of fracture. The paired pectoralis muscles are capable of generating enormous force, work and power output during normal flight (Tobalske et al., 2003) and these outputs increase dramatically during vigorous wing-flapping (Tobalske and Dial, 2000; Jackson and Dial, 2011). Comparable wing-flappingis often observed in commercial laying hens that slip from a perch or aviary tier and try to regain their footing (personal observation, M Toscano). Three-dimensional force-balance calculations (Hutchinson et al., 2005; Baier et al., 2006) should be used to test for effects of keel deformity upon bone loading during pectoralis muscle contraction; particularly those observed during episodes where balance is lost or panics (see Recommendation \#5). Deviated keels may lead to KF indirectly by complicating balance maneuvers, an additional topic which deserves investigation. 


\section{Recommendation 4 - Investigate the role of bird development in KBD susceptibility}

It is of prime importance to learn more about development of locomotor and cognitive skills as these contribute towards the ability of hens to navigate within the home system. It is doubtful that the traditional aviary rearing system, where chicks are kept confined to platforms for the first four weeks after which the sides are opened, is the best system to prepare birds for aviary housing (Kozak et al., 2015). Under natural conditions, locomotor capacity is critical in Galliformes as they are confronted with immediate challenges to escape predators, search for food and seek shelter (Dial and Jackson, 2011). Beginning at six days post-hatching, wild Galliformes will readily flap their wings to produce aerodynamic forces that enhance hindlimb function while moving up inclines, a behavior called wing-assisted incline running (WAIR) (Dial, 2003; Tobalske and Dial, 2007; Dial et al., 2008). Adult Galliformes may prefer WAIR rather than flight to reach an elevated area in a complex, natural habitat (Dial and Jackson, 2011). A better understanding of this process in commercial strains could be helpful to design juvenile and/or adult hen housing systems that improve locomotor abilities (Leblanc et al., 2015). For instance, variable-engineered systems would be suitable for accommodating the birds as they develop, using more ramps and adjustable angles with increasing age. A potential advantage of WAIR compared with flight may be that whole-body kinetic energy is less during WAIR (Tobalske and Dial, 2000 ; 2007), a benefit that could reduce the risk of KBD due to accidental impact with the housing environment. Additionally, increased wing-flapping during development may assist in improving balancing abilities (Filipa et al., 2010) while greater activity is known to correlate with bone strength (Rath et al., 2000). Beyond musculo-skeletal development, juvenile birds using WAIR will likely learn neuromuscular coordination that will be useful for negotiating three-dimensional structures in adulthood, an impairment suggested by Gunnarsson et al. (2000). Research in this area will help to identify optimum rearing conditions likely to protect birds from cognitive impairment in adulthood.

\section{Recommendation 5 - Investigate the role of escape reactions as a source of KF}

Efforts should be made to understand the damage resulting from sudden escape reactions, or during panic. Escape is normally triggered by a situation that is, or is perceived to be, life-threatening and thus is not 'normal' in the context of commercial poultry husbandry, though has been documented (Richards et al., 2012). 'Escapes' resemble the pattern seen in Galliformes involving take-off using high-frequency, high-amplitude wing beats that feature enormous power output (Tobalske and Dial, 2000; Tobalske et al., 2003), a quick return to the ground using a glide, and then resumption of walking or running. Given that the response is one of last resort, its manifestation is likely to exceed the keel's morphological capacity. Additionally, escape flights will not allow for the precise navigation required in housing systems. A more thorough understanding of the causes of escapes is necessary, including the roles of genetic selection and stockmanship, and the effects of dim lighting conditions and intra-bird spacing (Tillmann, 2009).

A comparative evolutionary approach could further aid investigation regarding the role of escape reactions as a source of damage. A museum survey of wild birds of different species showed that $4.5 \%$ out of a sample size of 6,212 specimens had sustained and survived bone injuries of which clavicle injuries were the greatest in number, especially 
in smaller birds, and were attributed to collisions with solid objects (Tiemeier, 1941). The sample included 45 birds in the Phasianidae, the family that includes the chicken, with an incidence rate of $10 \%$ in this family. These percentages are far lower than incidence rates of KBD in layer hens, but they do suggest that the escape flight of birds in the Phasianidae (Tobalske and Dial, 2000) may be correlated with bone damage. An alternative explanation, however, is that some damage reported by Tiemeier (1941) was due to gunshot, as many species in the Phasianidae are gamebirds.

\section{Recommendation 6 - Investigate genetic capacity to reduce KBD}

The role of genetics as a contributing factor in KBD dates back to work by Hyre (1955) who showed that the tendency to develop keel deformities was heritable by successfully selecting for and against KBD over six generations. Even earlier, Warren (1937) showed that crooked keel bones (in comparison to straight keels) had a reduced ash content which he suggested was a causal factor. In considering the scope for genetic selection against KBD, we must first determine what traits should be selected where possibilities include: stronger bones, improved physical ability, and increased docility. Alternatively, as KBD is a relatively complex trait with a number of genetic and environmental factors playing a role, genomic selection should be considered (Fulton, 2012) by carefully monitoring the incidence of KBD in a large population of laying hens and then comparing genomic information of hens with and hens without KBD. One of the strengths of this approach is that it does not target a single factor, e.g. bone strength, but focuses on the actual presence or absence of damage. In theory, the associated mechanism(s) is (are) selected in the process of identifying birds with the desired trait. A challenge with the genomic approach is that it requires a large sampling population $(>5,000)$ of which a clear KBD phenotype is needed. However, once the genomic fingerprint of a hen with no $\mathrm{KBD}$ is acquired, no further phenotypic measurements are required for the selection program (Eggen, 2012). Although breeding for reduced KBD is attractive, one should be aware of possible linkages and trade-offs with other traits, e.g., reduced egg shell thickness and egg breaking strength (Stratmann et al., in press). Whitehead (2004b) provides an excellent review of the relationship between skeletal integrity and egg quality.

\section{Recommendation 7 - Investigate housing adaptations that affect frequency of KBD}

Large differences between housing systems in the incidence KF indicate that housing design and/or management plays a key-role (Rodenburg et al., 2008; Wilkins et al., 2011). Perches have received particular attention. As an indication that perches have a causal role in the occurrence of $\mathrm{KBD}$, higher rates were reported at end of lay for hens in conventional cages with (92\%) compared to those without (83\%) metal perches (Hester et al., 2013). Similarly, Wilkins et al. (2011) reported a 10-34\% increase in KF when perches were added in an organic mobile system. Often, round metal perches are used, which may not offer hens adequate support for their grip. Perches with slightly larger diameters and those made from more flexible materials (wood, rubber) have been suggested to be more capable of absorbing forces during impact and preventing KBD (Pickel et al., 2010; 2011). Perches covered with a soft rubber layer were successful in reducing the number of keel damage within a commercial aviary suggesting the benefit of this option (Stratmann et al., 2015b), possibly not only by reducing the pressure on the 
keel, but also by providing a cushion and improved grip when landing (Scholz et al., 2014). Perches as a source of fracture is discussed in more detail by Sandilands et al. (2009).

Apart from perches, the three-dimensional environment of the hens has to be designed so that it allows the hens to navigate between the different parts of the system. In most commercial aviary systems, improvements are possible that would improve hens' possibilities for safely navigating through the system. One option is to add ramps to aid transition between tiers. Stratmann et al. (2015a) showed that adding ramps to a commercial aviary system reduced falls by $55 \%$, collisions by $41 \%$ and keel fractures by $24 \%$, while movements between tiers increased by $44 \%$. The width of the corridors between the different rows within systems also needs further attention. If the corridor width is at the limit of the birds' navigational ability, it may cause increased collisions due to misjudged jumps (Heerkens et al., 2014).

Another factor to be considered when determining optimum housing is lighting. In many commercial laying hen operations, light intensity is kept at a relatively low level, especially in flocks that are prone to develop feather pecking. Birds need sufficient light and contrast to make an appropriate jump and safe landing (Moinard et al., 2004b). The timing of the light transition also seems important: Stratmann et al. (2013) reported that vertical movements occurred mainly during a dusk phase when hens usually move to a perching spot for the night. A sudden switch from light to dark periods may increase the risk of KF during this time. Hence, a gradual dawn- and dusk should be investigated as a possible means of reducing KF. Lastly, Heerkens et al. (2014) found flooring type to also be a factor where wire flooring had greater frequency of KF compared with plastic flooring, though the underlying causes need to be explored.

\section{Recommendation 8 - Investigate nutritional solutions to reduce KBD}

Solutions should include changes in bird management and nutrition. The high incidence of KF in cages (Hester et al., 2013) could point to a calcium shortage. Egg shell formation takes place during the night and hens need a large amount of calcium at this time to produce an eggshell each day. Hens can mobilise this calcium partly from their bones, but they need to restore their supply, otherwise the risk osteoporosis (Whitehead and Fleming, 2000). One way to supply hens with calcium during the night is to give them daytime access to calcium sources with larger particle sizes, such as grit or shells, which will then be digested during the night. Larger particle sizes of calcium has been shown to benefit skeletal health (Cheng and Coon, 1990; Guinotte et al., 1995) including that of the keel (Fleming et al., 1998), though usage of this technique varies due to multiple factors including damage to feeding equipment and birds selectively eating the larger particles. Thus, there may be a benefit in supplying grit separately, or developing other sources of calcium that help the hens to restore their supplies and prevent bone weakness. Other nutritional changes could involve incorporation of omega-3 content into the diet which has been shown to result in reduced fracture incidence (Toscano et al., in press; Tarlton et al., 2013) possibly by modulating bone metabolism and modeling (Liu et al., 2003; Watkins et al., 2003; Baird et al., 2008). 


\section{Recommendation 9 - Investigate and quantify KBD and production losses}

Physical conditions that are associated with pain can, if severe enough, induce redistribution of endogenous resources and derail physiological processes that ensure long-term survival, a classical criterion for compromised welfare (Moberg, 1985; Broom, 1991). More specifically, Prunier et al. (2013) advocated changes in productivity as an indication of pain and potentially for compromised welfare. As mentioned before, recent work has shown that individual birds with fractures housed in large groups ( $\sim 350$ birds/ group) produced eggs that were characterised with reduced breaking strength and thinner shells (Toscano, in press). This response may represent a diversion of resources where minerals (e.g. calcium) and energy, normally directed towards egg production, must consequently be reallocated to the process of healing bone (Thiruvenkadan et al., 2010). Similar results for altered egg production in individual birds were found by Nasr et al. (2012b; 2013), although this was assessed in non-commercial conditions (i.e., individual hens isolated in separate cages) in order to link the egg and hen. More critically, work by Nasr et al. (2012b; 2013), as well as that by Toscano (in press), did not control for natural variation in bird laying capacity. The lack of preKF data leaves open the possibility that birds prone to KF may produce less and weaker eggs independent of whether KFs occurred. Differences in egg character after fracture must be shown to be absent beforehand if the measure is to be a valid indicator of welfare. Interestingly, others have been unable to demonstrate a link between egg production and keel fracture at the flock level (Heerkens et al., 2013). The lack of a relationship could be due to high flock-level variance rather than the absence of an effect, indicating the need for research at bird level responses. Alternatively, Whitehead (2004b), reviewing several studies that examined individually housed birds bred for different bone qualities, suggested that little correlation existed between egg production and bone quality. The finding was supported by Gebhardt-Henrich and Fröhlich (2012) who reported more fractures in hens which laid their first egg earlier. As an additional complication in linking the occurrence of fractures with production data, the period in which fractures are seen to most dramatically increase (25 -35 weeks of age) is the one in which birds are coming off peak of lay, thus a drop in production is expected independent of fractures. Therefore, the predicted falloff in egg production resulting from KBD may be subsumed by the drop in egg production as the hen exits the peak of lay period.

Quantification of production endpoints and the loss of productivity associated with KBD can be used as a powerful means to assess changes in animal welfare. More so, because concern for animal welfare is not globally consistent (Lopez, 2007) with the strongest interest in Europe and North America, framing the problems of KBD in terms of productivity losses and compromised profit could provide alternative motivations that move towards an ultimate goal of reducing KBD. This particular argument is powerful as it does not diminish the reality that action on the grounds of compromised welfare is necessary, but rather adds a supplementary dimension that will drive stakeholders to effect change.

Interestingly, it is often suggested that KF result from bone that is weakened by the process of demineralisation to provide adequate amounts of calcium for egg shell formation. If correct, continued egg production should associate with a decrease in bone strength and an increase in the occurrence of KF. While this appears to be the case for the first 20 weeks of egg production, recent comparisons of several studies suggest that rates of fractures actually appear to flatten and possibly fall after 45 wks of age (Toscano et al., 2015; Tarlton et al., 2013; Stratmann et al., 2015b; Petrik et al., 2015). It is possible that this decrease could be attributed to altered behaviour, though use 
of an ex vivo impact testing protocol with dead hens (Toscano et al., 2013) identified a pattern of decreased susceptibility to fracture (Toscano et al., 2014) that mirrored the onfarm observations of live hens. Further research is needed to determine how this change in fracture occurrence relates to altered bone physiology and egg production during this period.

\section{Conclusions}

Keel bone damage represents a welfare and productivity problem for the laying hen industry and, while achievements have been made in understanding the nature and cause of occurrence, we remain far from resolving the issue. The current paper highlights areas of research that would achieve the goal of reducing KBD, encourage adoption of methods to improve the accuracy and reliability of reporting, and provide technical changes that could be adopted.

\section{Acknowlegements}

This manuscript is a product of discussion and collaboration between participants of the 2014 International Keel Bone Workshop held April 2014 in Zollikofen, Switzerland. Organized by the University of Bern, funding was gratefully received from: The Swiss National Science Foundation, The Federal Food Safety and Veterinary Office of Switzerland, the Biological and Biotechnology Sciences Research Council of the United Kingdom, and the Universities Federation for Animal Welfare. Workshop participants, in alphabetical order, were: Michael Appleby (World Animal Protection), Teresa Casey-Trott (University of Guelph, Canada), Rachel Dennis (University of Maryland, USA), Ernst Fröhlich (Federal Food Safety and Veterinary Office, Switzerland), Sabine Gebhardt (University of Bern, Switzerland), Alexandra Harlander (University of Guelph, Canada), Jasper Heerkens (Institute for Agricultural and Fisheries Research, Belgium), Patricia Hester (Purdue University, USA), Darrin Karcher (Michigan State University, USA), Ine Kempen (Proefbedrijf Pluimveehouderij, Belgium), Tine Lentfer (Bundesanstalt für Landwirtschaft und Ernährung, Germany), Maja Makagon (Purdue University, USA), Mohammed Nasr (Zagzig University, Egypt), Prafulla Regmi (Michigan State University, USA), Nadine Ringenberg (University of Bern, Switzerland), Bas Rodenburg (Wageningen University, The Netherlands), Victoria Sandilands (Scottish Rural Cottage, Scotland), Lars Schrader (Friedrich Loeffler Institute, Germany), Markus Schwab (University of Bern, Switzerland), Janice Siegford (Michigan State University, USA), Janja Širovnik (University of Bern, Switzerland), Ariane Stratmann (University of Bern, Switzerland), John Tarlton (University of Bristol, England), Bret Tobalske (University of Montana, USA), Simi Tomar (Central Avian Research Institute, India), Michael Toscano (University of Bern, Switzerland), Stephen Turner (British Egg Industry Council, Great Britain), Teun van de Braak (Hendrix Genetics), Tina Widowski (University of Guelph, Canada), Lindsay Wilkins (Amberly Animal Welfare Consulting, England), and Hanno Würbel (University of Bern, Switzerland). 
Keel bone damage: causes and solutions: A. Harlander-Matauschek et al.

\section{References}

BAIER, D.B., GATESY, S.M. and JENKINS, F.A. (2006) A critical ligamentous mechanism in the evolution of avian flight. Nature 445: 307-310.

BAIRD, H.T., EGGETT, D.L. and FULLMER, S. (2008) Varying ratios of omega-6: omega-3 fatty acids on the pre-and postmortem bone mineral density, bone ash, and bone breaking strength of laying chickens. Poultry Science 87: 323-328

BESTMAN, M. and WAGENAAR, J.P. (2014) Health and Welfare in Dutch Organic Laying Hens. Animals 4: 374-390.

BROOM, D.M. (1991) Animal Welfare: Concepts and measurements. Journal of Animal Science 69: 41674175.

T. CASEY-TrotT, T., heERKENS, J., PETRIK, M., REGMi, P., SCHRADER, L., TOSCANO, M.J. and WIDOWSKI, T. (in press) Methods for Assessment of Keel Bone Damage in Poultry. Poultry Science: in press.

CHENG, T.K. and COON, C.N. (1990) Effect of calcium source, particle size, limestone solubility in vitro, and calcium intake level on layer bone status and performance. Poultry Science 69: 2214-2219.

DIAL, K.P. (2003) Wing-assisted incline running and the evolution of flight. Science 299: 402-404.

DIAL, K.P. and JACKSON, B.E. (2011) When hatchlings outperform adults: locomotor development in Australian brush turkeys (Alectura lathami, Galliformes). Proceedings Royal Society Biological Sciences 278: $1610-1616$.

DIAL, K.P., JACKSON, B.E. and SEGRE, P. (2008) A fundamental avian wing-stroke provides a new perspective on the evolution of flight. Nature 451: 985-989.

EGGEN, A. (2012) The development and application of genomic selection as a new breeding paradigm. Animal Frontiers 2: 10-15.

FAWC (2010) Opinion on Osteoporosis and Bone Fractures in Laying Hens . Farm Animal Welfare Council, London.

FAWC (2013) An open letter to Great Britain Governments: Keel bone fracture in laying hens.

FILIPA, A., BYRNES, R., PATERNN, M.V., MYER, G.D. and HEWETT, T. (2010) Neuromuscular Training Improves Performance on the Star Excursion Balance Test in Young Female Athletes. Journal of Orthopaedic \& Sports Physical Therapy 40: 551-558.

FLEMING, R.H., MCCORMACK, H.A. and WHITEHEAD, C.C. (1998) Bone structure and strength at different ages in laying hens and effects of dietary particulate limestone, vitamin $\mathrm{K}$ and ascorbic acid. British Poultry Science 39: 434-440.

FULTON, J.E. (2012) Genomic selection for poultry breeding. Animal Frontiers 2: 30-36.

GEBHARDT-HENRICH, S. and FRÖLICH, E.K.F. (2012) Auftreten von Brustbeinfrakturen und individuelles Verhalten bei Legehennen, in: ERHARD, M., POLLMAN, U., PUPPE, B., REITER, K. \& WAIBLINGER, S. (Eds) KTBL, pp. 52-60 (Freiburg, Germany).

GUINOTTE, F., GAUTRON, J., NYS, Y. and SOURMARMON, A. (1995) Calcium solubilisation and retention in the gastrointestinal tract in chicks (Gallus domesticus) as a function of gastric acid secretion inhibition and of calcium carbonate particle size. British Journal of Nutrition 73: 125-139.

GUNNARSSON, S., YNGVESSON, J., KEELING, L.J. and FORKMAN, B. (2000) Rearing without early access to perches impairs the spatial skills of laying hens. Applied Animal Behaviour Science 67: 217-228.

HEERKENS, J., DELEZIE, E., KEMPEN, I., ZOONS, J., RODENBURG, T.B. and TUYTENS, F. (2013) Do keel bone deformations affect egg-production in end-of-lay housing hens housed in aviaries?, in: TAUSON, R., BLOKHUIS, H.J., BERG, L. \& ELSON, A. (Eds) 9th European Poultry Conference, pp.127 (Uppsala, Sweden).

HEERKENS, J.L.T., KEMPEN, I., ZOONS, J., DELEZIE, E., RODENBURG, T.B., AMPE, B. and TUYTTENS, F.A.M. (2014) Effect of aviary housing characteristics on laying hen welfare and performance. Proceedings of the 48th Congress of the International Society for Applied Ethology, VitoriaGasteiz, Spain pp. 158.

HEERS, A.M. and DIAL, K.P. (2012) From extant to extinct: locomotor ontogeny and the evolution of avian flight. Trends in Ecology and Evolution 27: 296-305.

HeSTER, P.Y., ENNEKING, S.A., HALEY, B.K., CHENG, H.W., EINSTEIN, M.E. and RUBIN, D.A. (2013) The effect of perch availability during pullet rearing and egg laying on musculoskeletal health of caged White Leghorn hens. Poultry Science 92: 1972-1980.

HUTCHINSON, J.R., ANDERSON, F.C., BLEMKER, S.S. and DELP, S.L. (2005) Analysis of hindlimb muscle moment arms in Tyrannosaurus rex using a three-dimensional musculoskeletal computer model: implications for stance, gait, and speed. Paleobiology 31: 676-701.

HYRE, H.M. (1955) The effect of heredity and environment on keel deformities in White Leghorns. West Virginia Agricultural Experiment Station Bulletin 381.

JACKSON, B.E. and DIAL, K.P. (2011) Scaling of mechanical power output during burst escape flight in the Corvidae. Journal of Experimental Biology 214: 452-461. 
KAPPELI, S., GEBHARDT-HENRICH, S.G., FROHLICH, E., PFULG, A. and STOFFEL, M.H. (2011) Prevalence of keel bone deformities in Swiss laying hens. British Poultry Science 52: 531-536.

KONDO, K.L. (2008) Osteoporotic vertebral compression fractures and vertebral augmentation. Seminars in interventional radiology. Thieme Medical Publishers pp. 413.

KOZAK, M., TOBALSKE, B., MARTINS, C., WERBEL, H. and HARLANDER-MATAUSCHEK, A. (2015) Chick- locomotion in a multilayer environment. Accepted in Poultry Science Association 104rd Annual Meeting, Kentucky, USA.

LEBLANC, C., TOBALSKE, B., WUERBEL, H. and HARLANDER-MATAUSCHEK, A. (2015) Locomotion skills of chicks over an inclined walkway. Accepted in Poultry Science Association 104rd Annual Meeting,Kentucky, USA.

LIU, D., VEIT, H.P., WILSON, J.H. and DENBOW, D.M. (2003) Long-term supplementation of various dietary lipids alters bone mineral content, mechanical properties and histological characteristics of Japanese quail. Poultry Science 82: 831-839.

LOPEZ, J. (2007) Animal Welfare: Global Issues, Trends and Challenges. Scientific and Technical Review, Vol. 24 (2). Canadian Veterinary Journal 48: 1163-1164.

MOBERG, G.P. (1985) Biological response to stress: Key to assessment of well-being, in: MOBERG, G.P. (Ed) American Physiological Society, pp. 28-49 (Bethesda, MD).

MOINARD, C., STATHAM, P. and GREEN, P.R. (2004a) Control of landing flight by laying hens: implications for the design of extensive housing systems. British Poultry Science 45: 578-584.

MOINARD, C., STATHAM, P., HASKELL, M.J., MCCORQUODALE, C., JONES, R.B. and GREEN, P.R. (2004b) Accuracy of laying hens in jumping upwards and downwards between perches in different light environments. Applied Animal Behaviour Science 85: 77-92.

NASR, M.A.F., MURELL, J. and NICOL, C.J. (2013) The effect of keel fractures on egg production, feed, and water consumption in individual laying hens. British Poultry Science 54: 165-170.

NASR, M.A.F., MURELL, J., WILKINGS, L.J. and NICOL, C.J. (2012a) The effect of two classes of opioid drug on the landing ability of laying hens with and without keel fractures, in: UFAW Animal Welfare Conference: Recent Advances in Animal Welfare Science III,York, UK.

NASR, M.A.F., MURELL, J., WILKINGS, L.J. and NICOL, C.J. (2012b) The effect of keel fractures on egg production parameters, mobility and behaviour in individual laying hens. Animal Welfare 21: 127-135.

NASR, M.A.F., MURELL, J., WILKINGS, L.J. and NICOL, C.J. (2012c) Do Laying Hens with Keel Bone Fractures Experience Pain? PLoS One 7: e42420.

NASR, M.A.F., MURELL, J., WILKINGS, L.J. and NICOL, C.J. (2015) The effects of two non-steroidal anti-inflammatory drugs on the mobility of laying hens with keel bone fractures. Veterinary Anaesthesia and Analgesia 42: 197-204.

PETRIK, M.T., GUERIN, M.T. and WIDOWSKI, T.M. (2015) On-farm comparison of keel fracture prevalence and other welfare indicators in conventional cage and floor-housed laying hens in Ontario, Canada. Poultry Science 94: 579-585.

PICKEL, T., SCSHOLZ, B. and SCHRADER, L. (2010) Perch material and diameter affects particular perching behaviours in laying hens. Applied Animal Behaviour Science 127: 37-42.

PICKEL, T., SCSHOLZ, B. and SCHRADER, L. (2011) Pressure load on keel bone and foot pads in perching laying hens in relation to perch design. Poultry Science 90: 715-24.

PRUNIER, A., MOUNIER, L., LE NEINDRE, P., LETERRIER, C., MORMÈde, P., PAULMIER, V., PRUNET, P., TERLOUW, C. and GUATTEO, R. (2013) Identifying and monitoring pain in farm animals: a review. Animal 7: 998-1010.

RATH, N.C., HUFF, G.R., HUFF, W.E. and BALOG, J.M. (2000) Factors regulating bone maturity and strength in poultry. Poultry Science 79: 1024-1032.

RICHARDS, G.J., BROWN, S.N., BOOTH, F., TOSCANO, M.J. and WILKINS, L.J. (2012) Panic in freerange laying hens. Veterinary Record 170: 519.

RODENBURG, T.B., TUYTTENS, F.A.M., DE REU, K., HERMAN, L., ZOONS, J. and SONCK, B. (2008) Welfare assessment of laying hens in furnished cages and non-cage systems : an on-farm comparison. Animal Welfare 17: 363-373.

SANDILANDS, V., MOINARD, C. and SPARKS, N.H.C. (2009) Providing laying hens with perches: fulfilling behavioural needs but causing injury? British Poultry Science 50: 395-406.

SCHOLZ, B., KJAER, J.B. and SRADER, L. (2014) Analysis of landing behaviour of three layer lines on different perch designs. British Poultry Science 55: 419-426.

SCHOLZ, B., RÖNCHEN, S., HAMANN, H., HEWICKER-TRAUTWEIN, M. and DISTL, O. (2008) Keel bone condition in laying hens: a histological evaluation of macro scopically assessed keel bones. Berliner und Münchener Tierarztliche Wochenschrift 121: 89-94.

SCOTT, G., LAMBE, N.R. and HITCHCOCK, D. (1997) Ability of laying hens to negotiate horizontal perches at different heights, separated by different angles. British Poultry Science 38: 48-54. 
STRATMANN, A., FROHLICH, E.K.F., GEBHARDT-HENRICH, S., HARLANDER-MATAUSCHEK, A., WÜRBEL, H. and TOSCANO, M.J. (2015a) Modification of aviary design reduces incidence of falls, collisions and keel bone damage in laying hens. Applied Animal Behaviour Science 165: 112-123.

STRATMANN, A., TOSCANO, M.J., FROHLICH, E.K.F., HARLANDER-MATAUSCHEK, A. and GEBHARDT-HENRICH, S. (2015b) Do soft perches reduce keel bone fractures in laying hens? PlosONe 10: e0122568.

STRATMANN, A., FRÖHLICH, E.K.F., GEBHARDT-HENRICH, S.G., HARLANDERMATAUSCHEK, A., WÜRBEL, H. and TOSCANO, M.J. (in press) Genetic selection to increase bone strength affects prevalence of keel bone damage and egg parameters in laying hens. Poultry Science: in press.

STRATMANN, A., FROHLICH, E., WÜRBEL, H. and GEBHARDT-HENRICH, S.G. (2013) Crashes of laying hens in aviary systems. Proceedings of the Joint Meeting of the 33rd International Ethological Conference (IEC) \& the Association for the Study of Animal Behavioir (ASAB) Conference,NewcastleGateshead, UK.

TARLTON, J.F., WILKINS, L.J., TOSCANO, M.J., AVERY, N.C. and KNOTT, L. (2013) Reduced bone breakage and increased bone strength in free range laying hens fed omega-3 polyunsaturated fatty acid supplemented diets. Bone 52: 578-586.

THIRUVENKADAN, A.K., PANNEERSElVAM, S. and PRABAKARAN, R. (2010) Layer breeding strategies: an overview. World's Poultry Science Journal 66: 477-502.

TIEMEIER, O.W. (1941) Repaired bone injuries in birds. Auk 58: 350-359.

TILLMANN, J.E. (2009) Fear of the dark: night-time roosting and anti-predation behaviour in the grey partridge (Perdix perdix L.). Behaviour 146: 999-1023.

TOBALSKE, B.W. and DIAL, K.P. (2000) Effects of body size on take-off flight performance in the Phasianidae (Aves). Journal of Experimental Biology 203: 3319-3332.

TOBALSKE, B.W. and DIAL, K.P. (2007) Aerodynamics of wing-assisted incline running in birds. Journal of Experimental Biology 210: 1742-1751.

TOBALSKE, B.W., HEDRICK, T.L., DIAL, K.P. and BIEWENER, A.A. (2003) Comparative power curves in bird flight. Nature 421: 363-366.

TOMASZEWSKI, P.K., VERDONSCHOT, N., BULSTRA, S.K. and VERKERKE, G.J. (2010) A comparative finite-element analysis of bone failure and load transfer of osseointegrated prostheses fixations. Annals of Biomedical Engineering 38: 2418-2427.

TOSCANO, M.J. (in press) The relationship between keel bone fractures and egg production for laying hens within large groups. Poultry Science Association 104rd Annual Meeting, Kentucky, USA.

TOSCANO, M.J., BOOTH, F., WILKINS, L.J., AVERY, N.C., BROWN, S.B., RICHARDS, G. and TARLTON, J.F. (2015) The effects of long (C20/22) and short (C18) chain omega-3 fatty acids on keel bone fractures, bone biomechanics, behaviour and egg production in free range laying hens. Poultry Science 94: 823-835.

TOSCANO, M.J., BOOTH, F., WILKINS, L.J., BROWN, S.B., RICHARDS, G. and TARLTON, J.F. (2014) Use of an impact tester to assess the likelihood of fractures occuring against key bird- and motionrelated factors. Proceedings of the 2014 Poultry Science Association Annual Meeting, Corpus Christi.

TOSCANO, M.J., WILKINS, L.J., MILBURN, G., THORPE, K. and TARLTON, J.F. (2013) Development of an ex vivo protocol to model bone fracture in laying hens resulting from collisions. (Witten, P.E., Ed.). PLoS One 8: e66215.

TOSCANO, M.J., BOOTH, F., WILKINS, L.J., AVERY, N.C., BROWN, S.B., RICHARDS, G. and TARLTON, J.F. (in press) The effects of long (C20/22) and short (C18) chain omega-3 fatty acids on keel bone fractures, bone biomechanics, behavior, and egg production in free-range laying hens. Poultry Science: in press.

WARREN, D.E. (1937) Physiological and genetic studies of crooked keels in chickens. Kansas Agricultural Experiment Station Technical Bulletin: 44.

WATKINS, B.A., LI, Y., LIPPMAN, H.E. and FENG, S. (2003) Modulatory effect of omega-3 polyunsaturated fatty acids on osteoblast function and bone metabolism. Prostaglandins Leukotrienes Essential Fatty acids 68: 387-398.

WHITEHEAD, C.C. (2004a) Skeletal disorders in laying hens: the problem of osteoporosis and bone fractures, in: PERRY, G.C. (Ed.) Welfare of the Laying Hen, pp. 259-270 (Wallingford, CABI Publishing).

WHITEHEAD, C.C. (2004b) Overview of bone biology in the egg-laying hen. Poultry Science 83: 193-199.

WHITEHEAD, C.C. and FLEMING, R.H. (2000) Osteoporosis in cage layers. Poultry Science 79: 10331041.

WILKINS, L.J., BROWN, S.N., ZIMMERMAN, P.H., LEEB, C. and NICOL, C.J. (2004) Investigation of palpation as a method for determining the prevalence of keel and furculum damage in laying hens. Veterinary Record 155: 547-549. 
Keel bone damage: causes and solutions: A. Harlander-Matauschek et al.

WILKINS, L.J., MCKINSTRY, J.L., AVERY, N.C., KNOWLES, T.G., BROWN, S.N., TARLTON, J. and NICOL, C.J. (2011) Influence of housing system and design on bone strength and keel bone fractures in laying hens. Veteterinary Record 169: 414. 